\section{A rare complication of myocardial infarction}

A 75-year-old patient was admitted with lightheadedness and feeling unwell for 5 days. He had no significant past cardiac history, and denied any chest pain or breathlessness. Electrocardiogram showed q waves with residual ST elevation in the inferior leads (Panel A figure 1). On examination, the patient was haemodynamically stable, but profoundly hypoxic with oxygen saturations of $67 \%$ on air refractory to oxygen therapy. He had raised jugular venous pressure, clear lung fields and a loud pan-systolic murmur. All the bloods including inflammatory markers were normal, but troponin Twas raised. Chest $\mathrm{x}$-ray and CTPA were normal. Echocardiogram revealed dilated and impaired right ventricle (RV) with severe tricuspid regurgitation and mild left ventricular dysfunction (see online supplementary video 1). This raised the possibility of inferior wall myocardial infarction with RVMI and a right-to-left shunt, which was confirmed on bubble contrast study (see online supplementary video 2). There was no target vessel for revascularisation; the patient's condition deteriorated rapidly and was deemed unsuitable for either surgical or percutaneous closure of shunt, and was treated conservatively.
The development of right-to-left shunt in the context of RVMI is very rare, the incidence of which is not known. Patients can present with hypoxia refractory to oxygen therapy in the absence of any other cause and paradoxical embolisation. Treatment is generally supportive with revascularisation of target artery where possible. There is no general consensus for shunt closure, as normally RV function improves and the shunt closes. Recognition of this condition and early diagnosis is critically important to prevent any life-threatening sequelae.

\section{Usha Rao, Mirela M Marinescu}

Department of Cardiology, West Suffolk Hospital, Suffolk, UK

Correspondence to Dr Usha Rao, SpR, Department of Cardiology, West Suffolk Hospital, Suffolk IP33 20Z, UK; drusharao@hotmail.com

- Additional data are published online only. To view these files please visit the journal online (http://dx.doi.org/10.1136/heartasia-2012-010183)

Competing interests None.

Patient consent Obtained.

Provenance and peer review Not commissioned; internally peer reviewed.

Heart Asia 2012;151. doi:10.1136/heartasia-2012-010183

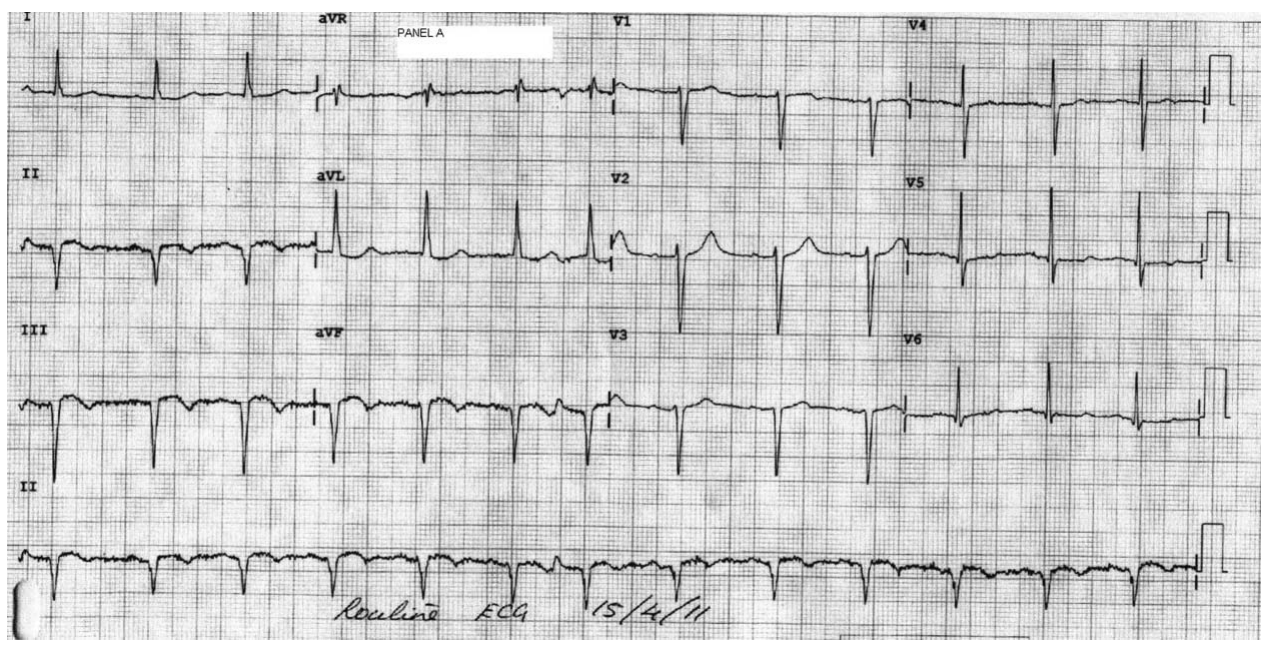

Figure 1 Panel A: Electrocardiogram showing q waves with residual ST elevation in the inferior leads. 